\title{
GRUPO REFLEXIVO PARA MULHERES VÍTIMAS DE VIOLÊNCIA DOMÉSTICA NO PODER JUDICIÁRIO DE RONDÔNIA
}

Resumo: Os registros de violência doméstica no Brasil cresceram nos últimos anos, conforme dados fornecidos pelo Conselho Nacional de Justiça $(\mathrm{CNJ})$. Para combater esse problema, sancionou-se a Lei Maria da Penha, $n^{\circ}$ 11.340, que entre seus mecanismos de coibição prevê a atuação de grupos de atendimento para homens (art. 30 e 45) e mulheres (art. 30) em contexto de violência doméstica. Em busca de compreender melhor o funcionamento e benefícios do atendimento psicossocial em formato de grupo para mulheres vítimas desse tipo de violência, realizouse esta pesquisa. $\mathrm{O}$ presente estudo trata de uma pesquisa qualitativa, descritiva e exploratória, realizada com 06 mulheres
Chaiene de Jesus Capeleline ${ }^{1}$ Helena Veloso de Melo Araújo ${ }^{2}$ Thainá Sampaio Ribeiro ${ }^{3}$ Leandro Aparecido Fonseca Missiatto ${ }^{4}$ atendidas pelo Grupo Reflexivo para Mulheres e Homens em Situação de Violência Doméstica - Aequalitas, realizado pelo Tribunal de Justiça do Estado de Rondônia, comarca de Pimenta Bueno. Aplicou-se um questionário sociodemográfico e de percepção sobre o funcionamento do grupo. Os resultados demonstram que o grupo influiu de modo positivo na vida das participantes com relatos de transformação no sistema de família, o que sugere a importância desse tipo de atendimento no Sistema de Justiça, dada sua eficácia e benefícios advindos de suas ações.

Palavras-chave: Violência Doméstica.

\footnotetext{
${ }^{1}$ Psicóloga pela Faculdade de Ciências Biomédicas de Cacoal (Facimed).

2 Psicóloga pela Faculdade de Ciências Biomédicas de Cacoal (Facimed).

${ }^{3}$ Psicóloga pela Faculdade de Ciências Biomédicas de Cacoal (Facimed)

${ }^{4}$ Mestre em Psicologia (Unir/RO), Docente curso de Psicologia da Faculdade de Ciências Biomédicas de Cacoal (Facimed). Analista Processual em Psicologia do Tribunal de Justiça de Rondônia
} 
Grupo Reflexivo. Gênero.

Abstract: The records of domestic violence in Brazil have grown in recent years, according to data provided by the National Justice Council. In order to combat this problem, the Maria da Penha Law No. 11,340 was enacted, which, among its mechanisms of restriction, provides for the participation of service groups for men (articles 30 and 45) and women (article 30) in the context of domestic violence. In order to better understand the functioning and benefits of group psychosocial care for women victims of this type of violence, this research was carried out. The present study deals with a qualitative, descriptive and exploratory study carried out with 06 women attended by the Reflective Group for Women and Men in Situation of Domestic Violence - Aequalitas, carried out by the Court of Justice of the State of Rondônia, Pimenta Bueno judicial district. A sociodemographic questionnaire and perception about the functioning of the group was applied. The results show that the group had a positive influence on the participants' lives with reports of transformation in the family system, which suggests the importance of this type of care in the
Justice System, given its effectiveness and benefits from its actions.

Keywords: Domestic violence. Reflective Group. Genre.

\section{Introdução}

É notável o crescimento da violência doméstica contra mulher no Brasil, conforme dados fornecidos pelo Conselho Nacional de Justiça (CNJ, 2017), só no ano de 2016 mais de 1 milhão de processos sobre violência contra a mulher tramitou na justiça. Esse dado corresponde a 01 processo para cada 100 mulheres.

A violência doméstica propicia diversos efeitos danosos aos envolvidos deixando rastros e sequelas, sejam eles de forma imediata ou tardia, uma vez que esse tipo de violência transcende a agressão física e engloba dimensões sociais e psicológicas das vítimas (OLIVEIRA et al., 2015).

Para conter o crescimento da violência doméstica, sancionou-se, em 2006, a Lei $\mathrm{N}^{\mathrm{o}}$. 11.340, conhecida como Lei Maria da Penha, cujo objetivo foi o de criar mecanismos para coibir a violência doméstica e familiar contra a 
mulher (CARNEIRO; FRAGA, 2012).

A criação da Lei fomentou discussões em torno desse tipo de violência e se tornou um marco legal no Brasil na luta contra a violência doméstica sofrida por mulheres.

No artigo 30 da Lei Maria da Penha está prevista a atuação multidisciplinar com as vítimas de violência doméstica, o objetivo é o desenvolvimento de um conjunto de ações para prevenir, orientar e encaminhar os envolvidos nesse tipo de fenômeno social. Para Narvaz e Koller (2006), é necessário investir no apoio e na compreensão da vivência das vítimas a fim de favorecer a informação, valorizar e incentivar a mudança, as resistências e denúncias dos abusos sofridos para que de fato se tenha um sistema de garantia de direitos e proteção contra a violência doméstica contra a mulher.

$\mathrm{Na}$ perspectiva de acompanhamento às vítimas, destaca-se a modalidade de atendimento psicossocial em formato de grupos. Para Matos et al. (2012), essa modalidade de atendimento psicossocial é vantajosa por quebrar o isolamento a que essas mulheres estão sujeitas, validar experiências individuais, dar e receber apoio emocional em uma rede de identificação.

Este artigo é resultado de uma pesquisa realizada com mulheres que participaram de um grupo reflexivo para vítimas de violência doméstica desenvolvido pelo Tribunal de Justiça de Rondônia na comarca de Pimenta Bueno cujo objetivo foi o de verificar a percepção das participantes sobre $\mathrm{o}$ funcionamento e benefícios do grupo. A princípio, apresentam-se uma reflexão teórica sobre a violência doméstica e o atendimento psicossocial na modalidade de grupo, após expõem-se os resultados e discussão das entrevistas realizadas.

\section{Violência doméstica}

Caracteriza-se como violência doméstica atos instaurados no lar, podendo estes ser cometidos por familiares ou não, em que o agressor resida em um mesmo ambiente domiciliar que a vítima. Esse tipo de violência é muito comum no Brasil e frequentemente as vítimas são mulheres. Segundo dados do CNJ, em 2016 tramitaram no Judiciário pouco mais de 1.190 processos referentes à violência doméstica contra a mulher, o que mais 
ISSN | 2179-7137 | http://periodicos.ufpb.br/ojs2/index.php/ged/index

chama atenção é que esses números cresceram consideravelmente, só nos dois anos seguintes a 2016 o total de casos atendidos no Judiciário aumentou em 13\% (CNJ, 2016; 2017), mesmo com a ampliação da Lei Maria da Penha e a sansão da Lei do Feminicídio (Lei Nº 13.104/2015).

Segundo dados da Organização Pan-Americana de Saúde (OPAS), órgão vinculado à Organização Mundial de Saúde que trabalha com os países das Américas, tendo em vista melhorar a saúde e qualidade de vida de suas populações, a prevalência no Brasil de violência física e/ou sexual impetrada pelo parceiro em algum momento da vida oscila de uma em sete mulheres, o que corresponde a uma variação de $14 \%$ a $17 \%$ da população feminina brasileira (OPAS, 2018). No estado de Rondônia, a incidência de violência doméstica contra mulher cresceu mais que a média nacional $(13 \%$ e $34 \%$ para violência doméstica e feminicídio, respectivamente). Conforme dados do CNJ, entre 2016 a 2018, houve um aumento de $55 \%$ em registros oficiais de violência doméstica e de $470 \%$ de feminicídio.

Esse panorama insere a violência contra a mulher como um fenômeno de saúde pública (PINTO et al., 2017) e como problema de saúde coletiva carece de medidas de cunho legal, político e social para que o enfrentamento seja eficiente e permanente. Todavia, a elaboração de políticas públicas para a superação desse problema caminha na contramão da realidade brasileira. Segundo informações disponibilizadas pelo Siga Brasil (2019), sistema de informações sobre orçamento público federal, entre 2014 e 2017, houve uma redução no orçamento das políticas para as mulheres em pouco mais de $62 \%$ e nos valores para atendimento às mulheres em situação de violência os cortes chegaram a 78,95\%. Fatores como esses colocam em xeque a eficiência da Lei Maria da Penha, já que a natureza multifatorial da violência contra a mulher exige investimento maciço no aprimoramento das redes de apoio às vítimas.

Para além dos números sobre a violência doméstica, alguns estudos têm se esforçado em compreender melhor os meandros de sua prática. Para Bittar e Kohlsdorf (2013), esse tipo de agressão ocorre em ciclos compostos por três fases: $1^{\text {a }}$ fase $\quad-$ tensão no relacionamento, constrangimento em 
ISSN | 2179-7137 | http://periodicos.ufpb.br/ojs2/index.php/ged/index

público, abusos verbais; $2^{\mathrm{a}}$ fase descontrole, as agressões propriamente ditas, tanto físicas como psicológicas; $3^{\mathrm{a}}$ fase - momento no qual o agressor diz se arrepender de tal ato, fazendo inúmeras promessas, demonstrando o medo de perder a companheira. Tal ciclo se repete inúmeras vezes fazendo com que aumente a intensidade da violência (BITTAR; KOHLSDORF, 2013).

Segundo Carmo e Moura (2010), quebrar com o ciclo da violência pode ser muito difícil para a mulher, pois ela vive momentos de constante crise emocional e psicológica, o que faz diminuir sua capacidade de fazer escolhas focadas no futuro e empoderamento. Para Fonseca et al. (2012), o que alimenta o ciclo de violência é a tolerância e autoculpa que surgem na mulher vítima da violência no lar, muitas vezes recursos utilizados pelos agressores para manter as vítimas vinculadas ao sistema de abusos e agressão.

Em um estudo quantitativo conduzido por Lucena et al. (2016), que teve como objetivo analisar o ciclo da violência doméstica contra a mulher, tendo como amostra 427 mulheres residentes em João Pessoa/PB, identificou-se, por meio de instrumentos sobre qualidade de vida (Who Vaw Study e Whoqol Bref), que o meio ambiente foi o que obteve menor média. Esse quesito verifica questões sobre ambiente físico, recursos financeiros, moradia, entre outros, e indica que o lar é a dimensão de menor controle das vítimas e sugere que a permanência da violência doméstica esteja associada à dependência financeira da maioria das mulheres, condições de moradia e vida social, ocasionando relações de submissão e fortalecimento do ciclo de violência em que estão inseridas.

Nesse contexto, alguns fatores se destacam como elementos associados à violência doméstica, dentre eles o álcool, escolaridade, história familiar de violência doméstica e pobreza (MARTINS; NASCIMENTO, 2017), fortalecendo, de modo geral, o ciclo da violência contra a mulher. Conforme estudo qualitativo realizado por Vieira et al. (2014), com 13 mulheres que realizaram denúncia de violência doméstica no interior do Rio Grande do Sul, o consumo abusivo de álcool pelo companheiro vulnerabiliza ainda mais as mulheres para situações de violência nas relações conjugais e familiares. 
ISSN | 2179-7137 | http://periodicos.ufpb.br/ojs2/index.php/ged/index

Outros fatores associados à violência contra a mulher são a baixa escolaridade e a pobreza (MADUREIRA et al. 2014; FERREIRA et al., 2016; SCOTT; OLIVEIRA, 2018). Os estudos demonstram a face social dessa violência em que a prevalência é maior em classes sociais menos favorecidas, o que implica de modo profundo o caráter social e político da violência doméstica impetrada contra as mulheres.

\section{Grupos de mulheres para} enfrentamento à violência doméstica

Grupos de atendimento ou apoio psicossocial não são uma novidade, desde a década de 1960 vêm se mostrando como uma alternativa eficaz para os mais diversos tipos de sofrimentos psicológicos (YALOM; LESZCZ, 2006). No Brasil, a Lei Maria da Penha reconhece essas atividades que podem ser executadas tanto com homens e mulheres quanto familiares que se encontram em contexto de violência contra a mulher. A legislação avança por reconhecer práticas comunitárias e dá acesso ao acolhimento e compartilhamento humano por meio de grupos focais.
200

O modelo de grupos para mulheres surgiu nas décadas de 60 e 70 do século passado e em sua maioria resultou dos movimentos feministas da época (WILSON, 1997). Esses grupos proporcionavam notoriedade ao sofrimento específico a que estavam sujeitas mulheres da época, além de estimulá-las conjuntamente à superação e enfrentamento às adversidades em decorrência de gênero.

Como passar dos anos, as práticas de grupo com mulheres cresceram em torno do mundo, evidenciando a importância das atividades coletivas para a superação de problemas de ordem complexa e multifatorial como é o caso da violência doméstica contra a mulher. Os grupos se tornaram uma ferramenta consistente no atendimento às vítimas de violência, por inúmeras vantagens, mas destaca-se uma inicial que reside no fato de que essa configuração de atendimento quebra o isolamento a que as mulheres vítimas de violência doméstica estão sujeitas (CIG, 2011).

Quanto à eficácia do atendimento na modalidade de grupos, Ramos e Oltramari (2010) realizaram uma pesquisa com um grupo de mulheres 
ISSN | 2179-7137 | http://periodicos.ufpb.br/ojs2/index.php/ged/index

vítimas de violência cujo objetivo foi o de promover discussões que propiciassem a reflexão das mulheres sobre novas formas de enfrentamento das situações de violência. Identificouse, por meio de relatos das participantes, que as mulheres passaram a buscar seus direitos de igualdade de gênero, não estavam se submetendo às agressões físicas e psicológicas de seus companheiros e estavam repensando suas atitudes em relação a eles. Os resultados indicam que o grupo foi capaz de promover condições para que as vítimas recuperassem seu empoderamento para enfrentamento às agressões e violações a que estavam submetidas.

Faria e Stein (2015) realizaram estudo com um grupo de atendimento social com oito mulheres em situação de violência doméstica e constataram, ao final de oito sessões, que as mulheres encontraram apoio social adequado para serem reinseridas no mercado de trabalho e modificarem suas condições econômicas. O estudo é, todavia, limitado em razão do tamanho da amostra e da quantidade de encontros, o que prejudica as avaliações inferenciais.
Cox e Stoltenberg avaliaram a eficácia de um programa de intervenção em um grupo dirigido a mulheres vítimas de violência doméstica. $\mathrm{O}$ estudo contou com uma amostra de 21 mulheres e foi alvo de uma metodologia experimental. As sessões fizeram uso de uma multiplicidade de estratégias, incluindo discussões de grupo, estratégias didáticas e técnicas cognitivas. Os autores concluíram que entre o grupo controle e o grupo terapêutico não possuíam diferencias fundamentais, todavia houve diminuição na ansiedade e melhora na autoestima, o que representa que o trabalho de grupo, ainda que com técnicas divergentes, possibilita mudanças psicológicas para seus usuários. A pesquisa, por apresentar um grupo de participantes pequeno e ausência de follow-up, é marcada por limitações nesse campo de estudos.

Ferro (2018) realizou estudo com o Projeto Abraço, do Poder Judiciário de Rondônia. O projeto atua com mulheres e homens em situação de violência doméstica e oportuniza atendimento terapêutico para os envolvidos. Os encontros abordam temas de papéis de gênero, ciclo da violência e desigualdade dos gêneros. Em seu estudo, Ferro 
ISSN | 2179-7137 | http://periodicos.ufpb.br/ojs2/index.php/ged/index

constatou que entre 2010 e 2016, dos 642 casos atendidos pelo projeto Abraço, apenas $10,1 \%$ dos casos apresentaram reincidência. Os resultados demonstram ser resolutivos os grupos reflexivos na superação da violência doméstica, contudo são necessários estudos para destacar quais das práticas de grupo se mostram mais efetivas nesse tipo de atendimento terapêutico.

Uma outra característica importante é que os grupos exigem o mínimo para seu funcionamento, uma sala confortável capaz de conservar o sigilo das conversas e um profissional treinado, o que reflete em baixos custos para sua implantação. Desse modo, a combinação de baixos custos e eficiência torna os grupos focais uma importante alternativa ao atendimento de mulheres vítimas de violência doméstica.

Por fim, o atendimento à mulher vítima de violência, realizado na modalidade de grupo, destaca-se por constituir-se como espaço de escuta, troca de experiências e reflexão visando, principalmente, ao estabelecimento de confiança entre as participantes. Tais grupos ainda podem beneficiar a formação de vínculos de solidariedade e a troca de ideias como subsídios na formação de soluções diante o problema enfrentado (AVANCI et al., 2017). Com a criação dos grupos de apoio para mulheres vítimas de violência doméstica, a negação e/ou minimização da violência são identificadas, reconhecidas e trabalhadas de forma apoiante e através da educação acerca das dinâmicas da violência. Dessa forma, a mulher pode explorar as razões que a levaram a permanecer em uma relação violenta visando à redução do seu sentimento de culpa (MATOS, 2012).

No entanto, ainda são poucos os estudos no Brasil que apresentam resultados sobre a prática do atendimento de grupo com mulheres vítimas de violência doméstica, carecendo de mais atenção para possíveis aperfeiçoamentos nessa modalidade de atendimento psicossocial.

\section{Método}

A pesquisa foi aprovada pelo Comitê de Ética e Pesquisa sob número 2.882.662, conforme preconizado pela Resolução no $n^{\circ}$ 466/12 do Conselho Nacional de Saúde. O estudo foi realizado no município de Pimenta Bueno/RO, com mulheres participantes do Grupo Aequalitas: Grupo de Reflexão 
ISSN | 2179-7137 | http://periodicos.ufpb.br/ojs2/index.php/ged/index

para Mulheres e Homens em Contexto de Violência Doméstica. O grupo foi fundado em 2017 pelo Tribunal de Justiça de Rondônia e é uma ação da $1^{\mathrm{a}}$ Vara Criminal de Pimenta Bueno, seus encontros são realizados em ciclos de 04 encontros cuja temática é equidade entre gêneros, Lei Maria da Penha, ciclo da violência e enfrentamento assertivo aos conflitos conjugais. As sessões para os homens ocorrem em separado as das mulheres, cada sessão é promovida por psicólogos e assistentes sociais do Núcleo Psicossocial do fórum daquela comarca. Os encontros têm duração de duas horas.

A amostra da pesquisa foi constituída de forma intencional e por conveniência. As participantes eram mulheres, exclusivamente atendidas pelo grupo de apoio, sendo no total 06 participantes.

Para alcance dos objetivos, aplicou-se um questionário socioeconômico elaborado pelos pesquisadores. $\mathrm{O}$ instrumento continha 09 questões de cunho social e econômico e 03 questões sobre a participação no grupo de apoio. O objetivo foi o de conhecer a realidade econômica e cultural das participantes a fim de dimensionar o perfil da amostra estudada e verificar as percepções quanto à participação no grupo. Todas as entrevistas foram realizadas individualmente a fim de estimular o depoimento livre e coletar dados, garantindo, assim, a privacidade e sigilo do conteúdo exposto pelas entrevistadas.

\section{Resultados e discussão}

A média de idade das participantes da pesquisa foi de 45 anos e o desvio padrão, de 6.75. Relacionado à raça, três participantes se consideraram pardas, três caucasianas e uma preta, dentre estas quatro se declararam casadas no momento da pesquisa e duas solteiras. Todas as participantes possuíam moradia própria e residiam com familiares, filhos, companheiros ou pais. Quanto à escolaridade, cinco participantes apresentaram possuir ensino médio incompleto e apenas uma ensino superior completo. No que corresponde à filiação, quatro das entrevistadas possuem filhos. Sobre a renda familiar, quatro participantes declararam possuir renda de até um salário mínimo e duas apresentaram renda acima de um salário mínimo. Por 
ISSN | 2179-7137 | http://periodicos.ufpb.br/ojs2/index.php/ged/index

fim, quanto à atuação profissional, quatro eram do lar, uma era funcionária pública e uma exercia atividade remunerada em comércio.

O perfil sociodemográfico da amostra estudada condiz com estudos que apontam uma predominância de mulheres vítimas de violência com baixa escolaridade e pertencentes à classe média ou baixa. Em estudo realizado por Marinheiro et al. (2003) na cidade de Ribeirão Preto/SP, com uma amostra de 265 mulheres, obtiveram-se os seguintes resultados: média de idade foi de 34,6 anos de idade; a maioria das participantes se declarou alfabetizada $(96,2 \%)$, sendo que a maior parte frequentou a escola até o ensino médio, $58,5 \%$ referiam ser de cor branca, 59,8\% estavam desempregadas ou mencionaram ser do lar, 58,5\% habitavam na casa própria e $40 \%$ pertenciam à classe $\mathrm{C}$.

Já em uma pesquisa desenvolvida por Zart e Scortegagna (2015), cujo objetivo foi o de identificar o perfil sociodemográfico de mulheres vítimas de violência doméstica, identificou-se um perfil de idade aproximada aos 33 anos e baixa escolaridade (74,64\%). Já em estudo realizado por Rodrigues
(2014) cujo objetivo também foi o de conhecer o perfil das mulheres vítimas de violência doméstica residentes na cidade de Sobradinho/DF, identificou-se também que se tratam de mulheres alfabetizadas, mas sem ensino superior, com filhos e sem trabalho remunerado.

Em um estudo conduzido por Mendonça e Ludermir (2017), cujo objetivo foi investigar a associação da violência por parceiros íntimos relatada contra as mulheres, em que participaram 390 mulheres da cidade do Recife/PE, identificou-se que a maior parcela das mulheres relatantes de violência possuía baixa escolaridade e vivia com renda inferior a um salário mínimo.

Desse modo, embora pequena a amostra deste estudo, há correspondência com outras pesquisas de base populacional que identificam a vítima de violência doméstica como uma mulher de classe média ou baixa, com filhos e baixa escolaridade (FILHO et al., 2014). Esses resultados demonstram que a violência contra a mulher exige enfrentamentos centrados em políticas públicas que garantam distribuição de renda, além de acesso e permanência à educação para que essa modalidade de violência seja efetivamente transposta. 
Sobre a percepção das participantes quanto ao grupo reflexivo, as entrevistadas avaliaram o grupo como positivo. Uma participante se referiu ao grupo da seguinte forma:

“[...] a participação no grupo foi importante, pois me deu consciência sobre o relacionamento abusivo $e$ me auxiliou na comunicação" (Participante $6)$.

Outra entrevistada se referiu como uma mudança de vida:

"[...] o grupo mudou minha
vida para melhor, pois
aprendi a enfrentar com
segurança a violencia que
sofria" (Participante 2).

Os relatos das participantes avaliam o grupo positivamente por considerar que a experiência de grupo thes possibilitou mudanças de comportamentos em situações conflitivas. A dinâmica terapêutica dentro de grupos focais torna possível a resolução de problemas comuns ao grupo e prevê a reinserção social e a estimulação da corresponsabilidade pela própria saúde (HEBERLE; OLIVEIRA, 2016).

Segundo Bezerra e Oliveira (2002), os grupos reflexivos permitem
205

aos usuários retornar vivências durante um processo criativo, permitindo a reorganização emocional do paciente. Assim sendo, quando uma participante do Aequalitas constata mudanças em sua compreensão sobre relacionamento abusivo, por exemplo, ela as faz auxiliada, provavelmente, pelos processos de grupo que permitem o contato com sua realidade e a reorganização de seus conteúdos emocionais, ampliando, desse modo, sua percepção sobre as experiências e construindo novas possibilidades de atuação em seu futuro.

Uma das entrevistadas apontou a contribuição do grupo de reflexão na tomada de decisão.

"[...] mesmo com a participação no grupo não houve avanços na nossa vida conjugal, mas depois de participar do grupo fortaleci minha decisão em separar, o divórcio saiu essa semana. Tenho buscado ajuda médica e psicológica, foram vários anos de agressão" (Participante 03)

Os grupos reflexivos têm por objetivo contribuir para que as participantes se sintam fortes e seguras para fazer as escolhas mais promissoras para sua saúde e bem-estar. Segundo 
Freire (1980), as atividades em grupos proporcionam aos sujeitos pensar soluções para seus dilemas, já que no encontro com outras pessoas percebem sua realidade não mais como um beco sem saída e passam a considerar suas realidades como um desafio humano que pode ser compreendido e experienciado positivamente.

Quando as integrantes de um grupo estão em uma roda reflexiva, não estão passíveis apenas a conteúdos abordados didaticamente, mas estão sujeitas às muitas experiências compartilhadas por cada uma das participantes e passam, por meio disso, a perceber, em razão de similitudes e narrativas, conteúdos específicos de suas trajetórias no âmbito da violência doméstica.

"[...] durante os encontros eu percebi que minha história se parece com a de outras mulheres e que a gente viu, na maioria das vezes, a violência na casa de nossos pais, em nossos casamentos só demos continuidade." (Participante 05)

Segundo Yalom e Leszcz (2006), as pessoas que iniciam em um grupo chegam com o pensamento perturbador que somente elas passam por certos eventos de sofrimento e problemas, contudo, apesar da complexidade dos problemas humanos, certos denominadores comuns são claramente evidentes entre os indivíduos e os membros de um grupo logo percebem suas semelhanças. Esse princípio é descrito, segundo Yalom, como universalidade e sua potência curativa está justamente nas semelhanças das histórias de vidas que possibilitam aos participantes de grupos ecoar em si a história e experiências de vidas que favorecem compreender detalhes que antes não foram percebidos por eles mesmos.

A fala da Participante 05 ainda revela a importância que o grupo possuiu em evocar os elementos culturais da violência doméstica, muitas vezes inscrito na vida pregressa das participantes, quando ainda estavam em suas famílias de origem. A repetição de padrões comportamentais entre os membros de uma família é descrita como transgeracionalidade. Assim, a transgeracionalidade diz respeito a padrões relacionais que se repetem e perpetuam hábitos familiares, ainda que as pessoas envolvidas não percebam (FALCKE; WAGNER, 2005). Quando, 
ISSN | 2179-7137 | http://periodicos.ufpb.br/ojs2/index.php/ged/index

em um grupo as mulheres, que estão experimentando a violência ao longo de várias gerações, podem refletir não apenas sobre suas histórias atuais, mas como também a de seus ancestrais, levam à consciência a dimensão transgeracional da violência doméstica, o que pode implicar na observação mais acurada em seus novos relacionamentos.

Um outro benefício do grupo reflexivo foi a contribuição no empoderamento feminino. Segundo uma participante:

[...] "com o grupo eu me tornei mais segura e sei falar sobre meus sentimentos, permanecemos casados, mas depois de 26 anos de violência física, se hoje ele me bater novamente eu o denuncio, não ficarei mais calada". (Participante 01)

Quando mulheres vítimas de violência buscam por ajuda é comum sentirem dificuldades em expressar seus sentimentos em razão das peculiaridades da violência sofrida (GOMES, 2012). Nesse sentido, a escuta e o acolhimento em grupo podem promover um momento de reflexão das condições pessoais, deixando-as mais confiantes para a tomada de decisões quanto ao registro de ocorrência, além de empoderá-las para enfrentar a situação (AGUIAR; ROSO, 2016).

Garantir a autonomia e a livre expressão de mulheres que sofrem de violência é uma ferramenta para redução da reincidência de violência doméstica, uma vez que quanto mais forem capazes de manifestar suas necessidades e exigências conjugais de modo assertivo, as chances de serem vítimas de comportamentos agressivos de seus companheiros tendem a decair (CORRÊA; BENEGAS, 2017).

\section{Considerações finais}

O estudo foi realizado com mulheres que participaram do Grupo Aequalitas, promovido pelo Tribunal de Justiça de Rondônia na Comarca de Pimenta Bueno. Os dados coletados demonstraram que as entrevistadas perceberam como positiva a participação no grupo de reflexão e que a prática em grupo favoreceu para a consideração sobre suas experiências de violência e mudanças de comportamentos, firmando o empoderamento e a construção de novas posturas no enfrentamento à violência doméstica.

O perfil da amostra estudada 
ISSN | 2179-7137 | http://periodicos.ufpb.br/ojs2/index.php/ged/index

condiz com os dados populacionais apresentados por pesquisas recentes que indicam as condições sociais e educacionais como variáveis envolvidas na violência doméstica contra as mulheres. Sendo assim, a superação da violência no lar contra mulheres carece de investimento maciço em políticas públicas que garantam suficientes condições educacionais, profissionais e econômicas para que as mulheres se sintam fortalecidas em suas relações sociais e familiares.

O tamanho da amostra e a insuficiente descritividade das ações realizadas nas sessões do Grupo Aequalitas impedem que sejam realizadas inferências mais abrangentes, sugerindo a importância que esse tema seja mais explorado em futuros estudos, contribuindo consistentemente na luta contra a violência de gênero em âmbito familiar e no aperfeiçoamento das técnicas de atendimento psicossocial em grupos reflexivos.

\section{Referências}

Aguiar, Gracielle Almeida; Roso, Patrícia Lucion (2016). “O Empoderamento de Mulheres Vítimas de Violência Através do Serviço de
208

Acolhimento Psicológico: caminhos possíveis". In: XIII Seminário Internacional Demandas Sociais e Políticas Públicas na Sociedade Contemporânea - Mostra Internacional de Trabalho Científícos. Santa Cruz do Sul. Consultado a 22. 05.19, em http://online.unisc.br/acadnet/anais/inde x.php/sidspp/article/view/15876/3773.

Avanci, Joviana Quintes et al (2017). "Atendimento dos casos de violência em serviços de urgência e emergência brasileiros com foco nas relações intrafamiliares e nos ciclos de vida". Ciênc. saúde coletiva, Rio de Janeiro , 22(9), 2825-2840. Consultado a 22.05.19, em http://www.scielo.br/scielo.php?script=s ci_arttext\&pid=S1413$81232017002902825 \& \operatorname{lng}=\mathrm{en} \& \mathrm{nrm}=$ iso

Bezerra, D. B.; Oliveira, J. M. (2002). “A atividade artística como recurso terapêutico em saúde mental". Boletim da Saúde, 16 (2), 135-137.

Bittar, Danielle; Kohlsdorf, Marina (2013). “Ansiedade e depressão em mulheres vítimas de violência doméstica". Psicologia Argumento, 
ISSN | 2179-7137 | http://periodicos.ufpb.br/ojs2/index.php/ged/index

31(74), 447-456. Consultado a 04.07.19, em

https://periodicos.pucpr.br/index.php/psi cologiaargumento/article/view/20447.

Carmo, P. C. C. S.; Moura, F. G. A. (2010). "Violência doméstica: a difícil decisão de romper ou não com esse ciclo”. In: Seminário Fazendo Gênero 9, Florianópolis, Anais. Consultado a 15.01.19, em http://www.fazendogenero.ufsc.br/9/res ources/anais/1278278656_ARQUIVO_ VIOLENCIADOMESTICAADIFICIL DECISAODEROMPEROUNAOCOM ESSECICLO.pdf.

Carneiro, Alessandra Acosta; Fraga, Cristina Kologeski (2012). “A Lei Maria da Penha e a proteção legal à mulher vítima em São Borja no Rio Grande do Sul: da violência denunciada à violência silenciada”. Serv. Soc. Soc., 110, 369397. Consultado a 10.06.19, em http://www.scielo.br/scielo.php?script $=\mathrm{s}$ ci_arttext\&pid=S0101$66282012000200008 \& \operatorname{lng}=\mathrm{en} \& \mathrm{nrm}=\mathrm{iso}$

Comissão para a Cidadania e Igualdade de Género (2011). "Violência Doméstica: intervenção em grupo com mulheres vítimas". Porto. Consultado a 23.06.19, em https://www.cig.gov.pt/siic/wpcontent/uploads/2015/01/Viol\%C3\%Aa ncia-dom\%C3\%A9stica-

Interven\%C3\% A7\%C3\% A3o-emgrupo-com-mul-heresv\%C3\%Adtimas.pdf $>$.

Conselho Nacional de Justiça (2018). "Dados de violência doméstica e feminicídio no Brasil (2016 a 2018)”. Consultado a 22.05.19, em http://www.cnj.jus.br/files/conteudo/arq uivo/2019/03/c7bb60579ffe93584acf30 929c349c50.pdf $>$.

Conselho Nacional de Justiça (2017). “O Poder Judiciário na aplicação da Lei Maria da Penha”. Consultado a 21.05.19, em

http://www.cnj.jus.br/files/conteudo/arq uivo/2017/10/ba9a59b474f22bbdbf7cd4 f7e3829aa6.pdf.

Corrêa, Márcio; Benegas, Maurício (2019). "Violência doméstica, empoderamento feminino e a dinâmica do divórcio". Consultado a 17.06.19, em http://www.caen.ufc.br/wpcontent/uploads/2017/10/violencia- 
ISSN | 2179-7137 | http://periodicos.ufpb.br/ojs2/index.php/ged/index

domestica-empoderamento-feminino-ea-dinamica-do-divorcio.pdf.

Cox, J. W.; Stoltenberg, C. D. (1991). "Evaluation of a treatment program for battered wives". Journal of Family Violence, 6, 395-403, 1991.Consultado a 20.05.19,

em http://www.scielo.mec.pt/pdf/aps/v30n1 -2/v30n1-2a08.pdf.

Falcke, D.; Wagner, A. (2005). “A dinâmica familiar e o fenômeno da transgeracionalidade: Definição de conceitos". In A. Wagner (Org). Como se perpetua a família? A transmissão dos modelos familiares. Porto Alegre: EDIPUCRS.

Faria, Camilla Coimbra; Stein, Silvia Canaan de Oliveira (2015). "Grupo de atendimento social para mulheres em situação de violência doméstica e/ou familiar: trabalhando a autonomia econômica e financeira”. In: VII Jornada Internacional Políticas Públicas, São Luis. Consultado a 14.06.19, em http://www.joinpp.ufma.br/jornadas/join pp2015/pdfs/eixo7/grupo-deatendimento-social-para-mulheres-emsituacao-de-violencia-domestica-eou- familiar-trabalhando-a-autonomiaeconomica-e-financeira.pdf.

Ferreira, Rebeca Monteiro et al (2016). "Características de saúde de mulheres em situação de violência doméstica abrigadas em uma unidade de proteção estadual". Ciênc. saúde coletiva, 21(12), 3937-3946. Consultado a 16.06.19, em http://www.scielo.br/scielo.php?script $=\mathrm{s}$ ci_arttext\&pid=S1413-

$81232016001203937 \& \operatorname{lng}=\mathrm{en} \& \mathrm{nrm}=\mathrm{iso}$

Ferro, Àlvaro Kalix (2018). "Magistrado qualifica dissertação no mestrado em Direitos Humanos sobre a eficiência do Projeto Abraço, que oferta reuniões terapêuticas a agressores e vítimas de violência doméstica". Consultado a 09.05.19, em

http://emeron.tjro.jus.br/noticias/796$\underline{\text { magistrado-qualifica-dissertacao-no- }}$ mestrado-em-direitos-humanos-sobre-aeficiencia-do-projeto-abraco-que-oferta$\underline{\text { reunioes-terapeuticas-a-agressores-e- }}$ vitimas-de-violencia-domestica.

Filho, Adalberto Ayjara Dornelles et al (2014). Perfil da mulher vítima de violência doméstica no Brasil, Rio Grande do Sul e Caxias do Sul. In: XIII 
Encontro Aspectos Econômicos e Sociais da Região Nordeste do RS, Caxias do Sul. Consultado a 19.06.19, em

https://www.ucs.br/site/midia/arquivos/

$\underline{\text { TEC-10-Dornelles-Mincato-Grazzi- }}$

$\underline{\text { Violencia-domestica.pdf. }}$

Fonseca, Denire Holanda et al (2012). "Violência doméstica contra a mulher: realidade e representações sociais". Psicologia \& Sociedade, 24(2), 307-314. Consultado a 22.05.19, em http://www.scielo.br/pdf/psoc/v24n2/07. pdf.

Freire, Paulo (1980). "Educação como prática da liberdade". Rio de Janeiro: Paz e Terra.

Gomes, Nadirlene Pereira et al (2012). "Violência conjugal: elementos que favorecem o reconhecimento do agravo". Saúde debate, 36(95), 514-522. Consultado a 22.05.19, em http://www.scielo.br/scielo.php?script $=\mathrm{s}$ ci_arttext\&pid=S0103$11042012000400003 \& \operatorname{lng}=$ en $\&$ nrm=iso

Herbele, Andréia Yess, Oliveira, Lisandra Antunes (2016). “Grupos terapêuticos em saúde mental: uma modalidade na prática dos serviços de atenção a saúde mental". Consultado a 27.04.19, em http://www.uniedu.sed.sc.gov.br/wpcontent/uploads/2016/09/unoesc-

ANDR\%C3\%89IA-YESS-

\section{HEBERLE.pdf.}

Lucena, Kerle Dayana Tavares et al (2016). “Análise do ciclo da violência doméstica contra a mulher". J Hum Growth Dev, 26, 139-146. Consultado a 15.03.19, em http://pepsic.bvsalud.org/pdf/rbcdh/v26 n2/pt_03.pdf.

Madureira, Alexandra Bittencourt et al (2014). "Perfil de homens autores de violência contra a mulheres detidos em flagrante: contribuições para o enfrentamento". Escola Anna Nery, 18(4), 600-606. Consultado a 17.05.19, em

http://www.scielo.br/pdf/ean/v18n4/141 4-8145-ean-18-04-0600.pdf.

Marinheiro, André Luis Valentini et al (2006). "Prevalência da violência contra a mulher usuária de serviço de saúde". Rev. Saúde Pública, 40(4), 604-610. 
ISSN | 2179-7137 | http://periodicos.ufpb.br/ojs2/index.php/ged/index

Consultado a 22.05.19, em http://www.scielo.br/scielo.php?script=s ci_arttext\&pid=S0034$89102006000500008 \& \operatorname{lng}=\mathrm{en} \& \mathrm{nrm}=\mathrm{iso}$

Martins, Aline Gomes; Nascimento, Adriano Roberto Afonso do (2017). "Violência doméstica, álcool e outros fatores associados: uma análise bibliométrica". Arq. bras. psicol., 69(1), 107-121. Consultado a 06.05.19, em http://pepsic.bvsalud.org/scielo.php?scri $\mathrm{pt}=$ sci arttext\&pid=S1809-

$\underline{52672017000100009 \& \operatorname{lng}=\mathrm{en} \& \mathrm{nrm}=\mathrm{iso}}$

Matos, Marlene et al (2012). "Intervenção em grupo com vítimas de violência doméstica: uma revisão da sua eficácia”. Análise Psicológica, 30(1-2), 79-91. Consultado a 23.06.19, em http://www.scielo.mec.pt/pdf/aps/v30n1 -2/v30n1-2a08.pdf.

Mendonça, Marcela Franklin Salvador; Ludermir, Ana Bernarda (2017). "Violência por parceiro íntimo e incidência de transtorno mental comum". Revista de Saúde Pública, 51(32), 01-09. Consultado a 23.05.19, em

http://www.scielo.br/pdf/rsp/v51/pt_003
4-8910-rsp-S1518-

87872017051006912.pdf.

Narvaz, Martha Giudice; Koller, Sílvia Helena (2006). "Famílias e patriarcado: da prescrição normativa à subversão criativa". Psicol. Soc., 18(1), 49-55. Consultado a $\quad 10.06 .19, \quad$ em http://www.scielo.br/scielo.php?script=s ci_arttext\&pid=S0102-

$71822006000100007 \& \operatorname{lng}=\mathrm{en} \& \mathrm{nrm}=$ iso

Organização Pan-Americana da Saúde (2018). "Quase 60\% das mulheres em países das Américas sofrem violência por parte de seus parceiros". Consultado $\begin{array}{lll}\text { a } & 21.06 .19, & \text { em }\end{array}$ https://www.paho.org/bra/index.php?opt $\underline{\text { ion }=\text { com_content } \& \text { view }=\text { article } \& \text { id }=58}$ 12:quase-60-das-mulheres-em-paisesdas-americas-sofrem-violencia-porparte-de-seus-parceiros\&Itemid=820.

Pinto, Lucielma Salmito Soares et al (2017). "Políticas públicas de proteção à mulher: avaliação do atendimento em saúde de vítimas de violência sexual”. Ciênc. saúde coletiva, 22(5), 1501-1508. Consultado a $\quad 12.06 .19, \quad$ em http://www.scielo.br/scielo.php?script=s ci_arttext\&pid=S1413- 
$81232017002501501 \& \operatorname{lng}=\mathrm{en} \& \mathrm{nrm}=$ iso

Ramos, Maria Eduarda; Oltramari, Leandro Castro (2010). “Atividade reflexiva com mulheres que sofreram violência doméstica”. Psicologia Ciência e Profissão, 30(2), 418-427. Consultado a 10.06.19, em http://www.scielo.br/scielo.php?script=s ci_arttext\&pid=S1414$98932010000200015 \& \operatorname{lng}=\mathrm{en} \& \mathrm{nrm}=$ iso

Scott, Juliano Beck; Oliveira, Isabel Fernandes (2018). "Perfil de homens autores de violência contra a mulher: uma análise documental". Revista de Psicologia da IMED, 10(2), 71-88. Consultado a 25.06.19, em https://seer.imed.edu.br/index.php/revist apsico/article/view/2951/1993.

Siga Brasil (2019). "Página institucional". Consultado a 15.05.19, em

http://www9.senado.gov.br/QvAJAXZf c/opendoc.htm?document=senado\%2Fsi gabrasilpainelcidadao.qvw\&host=QVS \%40www9\&anonymous $=$ true $\&$ Sheet $=\mathrm{s}$ hOrcamentoVisaoGeral.

Vieira, Letícia Becker et al (2014).
"Abuso de álcool e drogas e violência contra as mulheres: denúncias de vividos". Revista Brasileira de Enfermagem, 67(3), 366-372. Consultado a 04.04.19, em http://www.scielo.br/pdf/reben/v67n3/0 034-7167-reben-67-03-0366.pdf.

Wilson, K. J. (1997). "When violence begins at home". CA: Hunter House Publishers.

Yalom, Irvin D.; Leszcz, Molyn (2006). "Psicoterapia de grupo: teoria e prática". Porto Alegre: Artmed.

Zart, Louise; Scortegagna, Silvana Alba (2015). "Perfil sociodemográfico de mulheres vítimas de violência doméstica e circunstâncias do crime". Perspectiva, 39(148), 85-96. Consultado a 19.0.19, em

http://www.uricer.edu.br/site/pdfs/persp ectiva/148_536.pdf 